\title{
DISSOCIATIVE AMNESIA WITH DISSOCIATIVE FUGUE- A CASE REPORT WITH 1-YEAR FOLLOWUP
}

\author{
Aditi Prasad Chaudhari1, Kaustubh Mazumdar², Shivraj Narsing Peste³, Divya Ramadas ${ }^{4}$, Asha Gaikwad5 $^{5}$
}

${ }^{1}$ Consultant, Department of Psychiatry, BARC Hospital, Mumbai.

${ }^{2}$ Consultant \& Head, Department of Psychiatry, BARC Hospital, Mumbai.

${ }^{3} 3^{\text {rd }}$ Year DNB Resident, Department of Psychiatry, BARC Hospital, Mumbai.

${ }^{4}$ Clinical Psychologist, Department of Psychiatry, BARC Hospital, Mumbai.

${ }^{5}$ Social Worker, Department of Psychiatry, BARC Hospital, Mumbai.

HOW TO CITE THIS ARTICLE: Chaudhari AP, Muzumdar K, Peste SN, et al. Dissociative amnesia with dissociative fugue- a case report with 1-year followup. J. Evolution Med. Dent. Sci. 2017;6(45):3559-3560, DOI: 10.14260/Jemds/2017/766

\section{PRESENTATION OF CASE}

A 53-year old man had gone missing for six months and therefore was evaluated to ascertain psychiatric fitness before joining work. On workup, he was found to be educated upto Class 9, a regular employee with no history of substance use or personality disorder of any kind. On $16^{\text {th }}$ December 2014 he went to the bank to withdraw money, following which he failed to return home. No suicidal note was found nor was any abnormal behaviour reported. Local search parties and the police were unable to trace him. Suddenly, after six months, on $7^{\text {th }}$ July 2015 , his colleague intimated his family members that he had received a call from the patient. They set out to look for him and found him wandering in a nearby garden. He was wearing the same clothes that he had been wearing on the day he left. Patient himself was tidy, clean shaven and properly kempt. He had lost quite a lot of weight, appeared weak and feverish and slightly perplexed. He recognised everyone and found his way around, but he could recall nothing of his whereabouts in the past six months. He could only recall that when he suddenly felt feverish and had shivering and vomiting, he remembered that he had to go to the hospital and that is how he recalled the details of his identity.

In November 2014, patient's wife was seriously ill and required prolonged admission in an intensive care unit. Patient was very stressed as regards to her survival. He spent long hours and sleepless nights attending to her and also attended work duties and home chores. On the said date, he went to the bank to withdraw some money, but became nervous when he found himself to be short of funds. This was the last thing that he could recall. Thereafter, he only recalled that he was at Panvel bus stand from where he made the call to his colleague. He had no memory of the interim period. Family members went to Panvel to inquire, but no reliable information could be ascertained.

\section{CLINICAL DIAGNOSIS}

He was admitted at our hospital and diagnosed with Vivax malaria, from which he made an uneventful recovery. On psychiatric evaluation, the stressors were elicited.

Financial or Other, Competing Interest: None.

Submission 25-01-2017, Peer Review 23-05-2017,

Acceptance 29-05-2017, Published 05-06-2017.

Corresponding Author:

Dr. Aditi Prasad Chaudhari,

Department of Psychiatry,

BARC Hospital, Anushakti Nagar,

Trombay, Mumbai-400094.

E-mail: draditi@barc.gov.in

DOI: $10.14260 /$ jemds $/ 2017 / 766$
He was cooperative and rapport could be established. He maintained eye contact and his attention was well sustained. His mood which was occasionally sad, improved as the days passed without any medications. His affect which was quite perplexed to begin with gradually became calmer. He denied any suicidal ideations or depressive cognition. He was relevant in his speech and exhibited no delusions or hallucinatory behaviour. He was oriented to time, place and person and his judgment and abstract thinking was normal. His Mini Mental Status Examination score was 26/30. His sleep and appetite were well maintained and patient mingled and interacted with everyone.

Rorschach test was done. There was low scatter and low number of responses, lack of movement responses and high response time, so the protocol was overall indicative of organicity. Bender Gestalt test was also indicative of organicity as seen from simplification, inversion and substitution. However, Magnetic Resonance Imaging Scan of the Brain showed no abnormality and Electroencephalogram was normal. Family members did not consent for Narco analysis, as the patient appeared asymptomatic to them.

A diagnosis of Dissociative Amnesia with the specification of Dissociative Fugue (300.13) was made as per Diagnostic and Statistical Manual $5 .{ }^{1}$ As per this classification system, the diagnosis of fugue is not as an independent entity but as a specific code added to the diagnosis of dissociative amnesia (300.12).

According to the International Classification of Diseases (ICD)-107 system of classification, when the features of fugue are present in addition to the symptoms of dissociative amnesia (F 44.0), an independent diagnosis of Dissociative fugue (F 44.1) can be made, which is applicable in this case.

At home, patient was completely independent in all activities of daily living. He denied any psychiatric symptoms and his mental status examination continued to be unremarkable. Hence, he was not started on any psychotropics and he was given fitness to resume work.

\section{MANAGEMENT AND FOLLOWUP}

This patient has been followed up for a period of one year. During this time, there have been no symptoms suggestive of any psychiatric illness or cognitive difficulties. His work functioning and regularity has been as good as earlier. His mental status examination continues to be unremarkable and the most recent mini mental status examination score was $27 / 30$. He continues to have complete amnesia about the period of fugue. Rorschach on followup showed average reality testing with an inadequate personality structure. Bender Gestalt test continued to show organicity as simplification, inversion and closure difficulty was noted. 


\section{DISCUSSION OF MANAGEMENT}

Dissociative amnesia is the inability to recall important personal information, usually of a traumatic or stressful nature that cannot be explained by ordinary forgetfulness, in the absence of overt brain pathology or substance use. ${ }^{2}$ It is considered to be the most common of the dissociative disorders with a prevalence ranging from $1.8 \%$ to $7.3 \%{ }^{3}$

The memory loss is episodic for a discreet period of time ranging from minutes to years. The amnesia is retrograde and new learning is not affected. It is most common in the third or fourth decades of life. ${ }^{2}$

It may be accompanied by dissociative fugue, which has a reported prevalence of $0.2 \% .4,5$ The onset is sudden ${ }^{6}$ and the patients wander in a purposeful way away from their homes or customary place of work and fail to remember important aspects of their identities such as their names, address or occupation. Only when they suddenly return to their former selves do they recall the time antedating the onset of fugue, but then they remain amnestic for the period of fugue itself. ${ }^{6}$ Fugue usually lasts for a period of hours to days, but it may last for many months and involve extensive travel as well. Generally, recovery is spontaneous and rapid. Recurrences have been reported. 6

This case meets all the criteria for dissociative amnesia with fugue. This patient had generalised amnesia of acute onset. Onset is often related to stressful life events, which in this case was the life-threatening illness in his wife. The episode was precipitated by the perceived financial crisis.

Stress as the cause of dissociative phenomenon can be explained from a neurobiological perspective. MacDonald et $\mathrm{al}^{7}$ have conducted a neuroscientific review of dissociative amnesia and fugue. In this paper, they have quoted studies to explain that explicit memory depends upon the hippocampus, which is uniquely affected by stress. During periods of stress, there may be a massive influx of glucocorticoids which may temporarily impair key neuronal structures like amygdala and hippocampus, which have a high density of glucocorticoid receptors. ${ }^{7}$ This may further lead to loss of connectivity and synchronous neural function or neuronal degeneration in some cases. ${ }^{7}$ Frontal cortical executive systems are also uniquely sensitive to stress and when impaired may inhibit information retrieval. ${ }^{7}$

In this case, patient was neither bankrupt nor in any debt, which he could have avoided by absconding. His past and current behaviour do not suggest any possibility of malingering. He was overwhelmed with prolonged stress to think of his options.

The amnesia was for autobiographical information as typically seen in dissociative fugue. Major neurocognitive impairment can be ruled out on account of unimpaired functioning and normal findings on imaging and mini mental status examination.

However, the patient did show evidence of organicity on psychological testing. Some studies have postulated an organic basis for dissociative disorders, citing dissociative amnesia as a reversible organic memory disorder. MacDonald et $\mathrm{al}^{7}$ have attempted to resolve the conceptual problems in the dichotomy between organic and functional amnesia by suggesting that it is possible that the patient has mild brain damage or dysfunction that may fall below the sensitivity threshold of imaging or functional assessments. They also suggest that demonstrable brain damage does not rule out an environmental trigger. In this case, only a prolonged followup may be able to throw light on the role of the subtle abnormalities noted. However, the role of the environmental stressor cannot be negated. Finally, other neurological conditions such as neuralgias, migraines, transient ischaemic attacks and transient global amnesia are also known to occur without morphological or functional evidence of damage. ${ }^{7}$

Psychosis was also ruled out on account of clear absence of any psychotic features. There was no history suggestive of seizures and the electroencephalogram was normal. The duration of amnesia and fugue was for more than six months, which made a seizure episode less likely. There was no history of evidence of any traumatic brain injury or substance use. Hence, these other differentials were also conclusively ruled out.

In this case, on resolution of fugue, no psychopathology was noted and the patient continues to have an unremarkable mental status on one year followup. Some authors have postulated that psychiatric comorbidities are seen in cases of dissociative fugue, ${ }^{8}$ but this was not observed in the present case.

This is a case of fugue which apart from being a rare case in itself concurs with the literature that fugue occurs in response to significant stress. The condition can occur by itself without any psychiatric comorbidities. However, subtle evidences of organicity may be evident in these cases. Neuropsychological testing may be one way to detect these subclinical abnormalities. However, only a prolonged followup would throw light on their role in the aetiology of this interesting phenomenon.

\section{FINAL DIAGNOSIS}

This is a case of Dissociative fugue, which apart from being a rare case in itself concurs with the literature that fugue occurs in response to significant stress.

\section{REFERENCES}

[1] Diagnostic and statistical manual of mental disorders. $5^{\text {th }}$ edn. DSM - 5: American Psychiatric Publishing 2013.

[2] Hales RE, Yudofsky SC, Roberts LW. Dissociative disorders. Textbook of Psychiatry. $6^{\text {th }}$ edn. The American Psychiatric Publishing 2015.

[3] Mushtaq R, Shoib S, Arif T, et al. First reported case of lorazepam - assisted interview in a young Indian female presenting with dissociative identity disorder and improvement in symptoms after interview. Case Reports in Psychiatry 2014;2014. Article ID 346939.

http://dx.doi.org/10.1155/2014/346939

[4] Gelder M, Harrison P, Cowen P. Shorter Oxford Textbook of Psychiatry. $5^{\text {th }}$ edn. New York: Oxford University Press 2006.

[5] Davison GC, Neale JM. Abnormal Psychology with cases. $8^{\text {th }}$ edn. New York: John Wiley \& Sons 2003.

[6] Sadock BJ, Sadock VA, Kaplan HI. Kaplan and Sadock's Synopsis of Psychiatry- Behavioural Sciences / Clinical Psychiatry. 9th Edition. Philadelphia, PA: Lippincott Williams and Wilkins 2003.

[7] MacDonald K, MacDonald T. Peas, please: a case report and neuroscientific review of dissociative amnesia and fugue. Journal of Trauma \& Dissociation 2009;10(4): 420-35.

[8] Coons PM. Psychogenic or dissociative fugue: a clinical investigation of five cases. Psychol Rep 1999; 84 (3 Pt 1):881-6. 